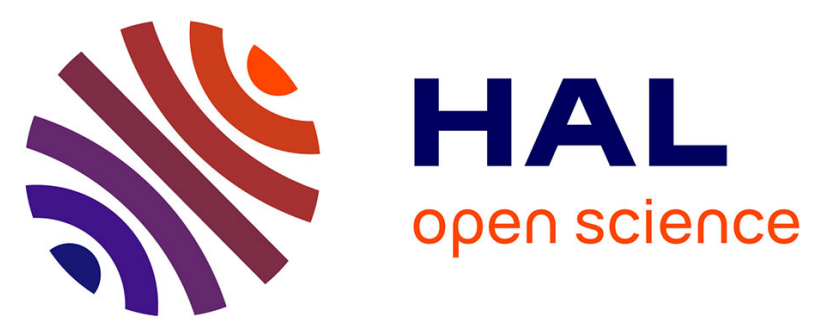

\title{
Ethanol and the Developing Brain: Inhibition of Neuronal Activity and Neuroapoptosis
}

\author{
Nailya Lotfullina, Roustem Khazipov
}

\section{To cite this version:}

Nailya Lotfullina, Roustem Khazipov. Ethanol and the Developing Brain: Inhibition of Neuronal Activity and Neuroapoptosis. Neuroscientist, 2017, 24 (2), pp.130-141. hal-01962291

\section{HAL Id: hal-01962291 \\ https://hal-amu.archives-ouvertes.fr/hal-01962291}

Submitted on 20 Dec 2018

HAL is a multi-disciplinary open access archive for the deposit and dissemination of scientific research documents, whether they are published or not. The documents may come from teaching and research institutions in France or abroad, or from public or private research centers.
L'archive ouverte pluridisciplinaire HAL, est destinée au dépôt et à la diffusion de documents scientifiques de niveau recherche, publiés ou non, émanant des établissements d'enseignement et de recherche français ou étrangers, des laboratoires publics ou privés.

\section{(c)(1)}

Distributed under a Creative Commons Attribution| 4.0 International License 


\title{
Ethanol and the Developing Brain: Inhibition of Neuronal Activity and Neuroapoptosis
}

The Neuroscientist

$1-12$

(C) The Author(s) 2017

Reprints and permissions:

sagepub.com/journalsPermissions.nav DOI: |0.1|77/I0738584|77|2667

journals.sagepub.com/home/nro

(S)AGE

\author{
Nailya Lotfullina ${ }^{1,2}$ and Roustem Khazipov ${ }^{1,2}$
}

\begin{abstract}
Ethanol induces massive neuroapoptosis in the developing brain. One of the main hypotheses that has been put forward to explain the deleterious actions of ethanol in the immature brain involves an inhibition of neuronal activity. Here, we review recent evidence for this hypothesis obtained in the somatosensory cortex and hippocampus of neonatal rodents. In both structures, ethanol strongly inhibits brain activity. At the doses inducing massive neuroapoptosis, ethanol completely suppresses the early activity patterns of spindle-bursts and gamma oscillations in the neocortex and the early sharp-waves in the hippocampus. The inhibitory effects of ethanol decrease with age and in adult animals, ethanol only mildly depresses neuronal firing and induces delta-wave activity. Suppression of cortical activity in neonatal animals likely involves inhibition of the myoclonic twitches, an important physiological trigger for the early activity bursts, and inhibition of the thalamocortical and intracortical circuits through a potentiation of GABAergic transmission and an inhibition of N-methyl-D-aspartate (NMDA) receptors, that is in keeping with the neuroapoptotic effects of other agents acting on GABA and NMDA receptors. These findings provide support for the hypothesis that the ethanol-induced inhibition of cortical activity is an important pathophysiological mechanism underlying massive neuroapoptosis induced by ethanol in the developing brain.
\end{abstract}

\section{Keywords}

ethanol, apoptosis, electroencephalogram, fetal alcohol syndrome, GABA, NMDA

\section{Introduction}

Ethanol is one of the most widely consumed drugs of abuse. While ethanol exerts numerous adverse actions in adults, its deleterious actions during fetal stages caused by maternal alcohol consumption are particularly strong and may qualitatively differ from the damage produced by ethanol in adults. After maternal ethanol consumption, ethanol can easily cross the placenta and reach the fetus. Depending on the gestational age, exposure to ethanol causes various malformations and lifelong deficits that can be grouped under the umbrella of the fetal alcohol syndrome disorders (FASD). The fetal brain is one of the main targets of ethanol and FASD patients display a number of neurological and behavioral deficits (Mattson and others 2011). Studies in FASD animal models have revealed that the deleterious effects of ethanol involve various mechanisms including anatomical malformation caused by apoptosis of progenitor cells during early fetal exposure to ethanol (Dunty and others 2001) and neuronal/glial apoptosis in differentiating cells, leading to ethanol induced injury during the critical developmental window of vulnerability, which coincides with the brain growth spurt period (Creeley and Olney 2013; Ikonomidou and others 2000; Olney and others 2002a; Olney and others 2002b). Interestingly, not only ethanol but also a number of other agents including ketamine, phencyclidine, benzodiazepines and barbiturates, anaesthetic agents and antiepileptic drugs exert similar neuroapoptotic actions during the brain spurt period (Bittigau and others 2002; Ikonomidou and others 1999; Ikonomidou and others 2000; Jevtovic-Todorovic and others 2003). This raised the hypothesis that a common mechanism stimulating neuroapoptosis during this critical developmental window of vulnerability exists, triggered by suppression of neuronal activity, since all these agents, including ethanol, are known to suppress excitatory synapses or potentiate inhibitory GABAergic synapses (Creeley and Olney 2013).

'INMED-INSERM, Aix-Marseille University, Marseille, France

${ }^{2}$ Laboratory of Neurobiology, Kazan Federal University, Kazan, Russia

\section{Corresponding Author:}

Roustem Khazipov, INMED-INSERM U90I, Aix-Marseille University, I 34 avenue de Luminy BPI3, I3273 Marseille, France.

Email: roustem.khazipov@inserm.fr 
The central element of this hypothesis is that physiological activity in developing networks prevents apoptosis and that suppression of this survival-promoting activity triggers the apoptotic process. Synaptic activity-dependent neuronal survival is induced by calcium entry through synaptic $\mathrm{N}$-methyl-D-aspartate NMDA receptors and voltage-gated calcium channels, that activates survival-promoting genes and enables neurons to build up a neuroprotective shield (Golbs and others 2011; Hagenston and Bading 2011; Heck and others 2008; Ikonomidou and others 1999; Kilb and others 2011; Leveille and others 2010; Mennerick and Zorumski 2000; Nimmervoll and others 2013) (Fig. 1A). Ethanol is thought to cause neuroapoptosis through an inhibition of the physiological activity and associated calcium transients. Inhibitory actions of ethanol on neuronal activity are complex as ethanol acts on multiple targets (Fig. 1B). Ethanol directly inhibits NMDA receptors (Lovinger and others 1989; Masood and others 1994; Wright and others 1996) and voltage-dependent calcium channels (Morton and Valenzuela 2016). In addition, ethanol potentiates $\operatorname{GABA}(\mathrm{A})$ receptors (Mody and others 2007), and increases quantal GABA release from interneurons (Galindo and others 2005). As a consequence of these complex inhibitory ethanol actions at the cellular level, excitatory/inhibitory balance at the network level is supposed to shift toward inhibition that would further aggravate a loss of calcium entry through NMDA channels as a result of reduced activity at glutamatergic synapses and reduced neuronal depolarization needed for a removal of magnesium block of NMDA channels, and through a reduced activation of the voltage-dependent calcium channels caused by reduced neuronal firing. In addition to these acute effects, long-term inhibitory mechanism may also involve hypoxic suppression of cortical activity caused by the ethanol-induced defects in angiogenesis (Girault and others 2017; Jégou and others 2012).

There are several excellent reviews describing various aspects of neuroapoptotic damage caused in the developing brain by ethanol and other agents, including the molecular cascades activated during ethanol-induced apoptosis, in detail (Creeley and Olney 2013; Farber and Olney 2003; Ikonomidou 2009; Luo 2012; Mennerick and Zorumski 2000; Nikolic and others 2013; Olney 2014; Olney and others 2004). Here, we will focus our review on the effects of ethanol on the early physiological patterns of activity expressed in the developing neocortex and hippocampus during the developmental "window of vulnerability" during which cortical neurons are at risk to the apoptotic effects of ethanol and will discuss these findings in context of ethanol-induced apoptosis.

\section{Early Patterns of Activity in the Developing Brain and Neuroapoptosis}

The developing brain expresses unique activity patterns that are thought to participate in a variety of developmental

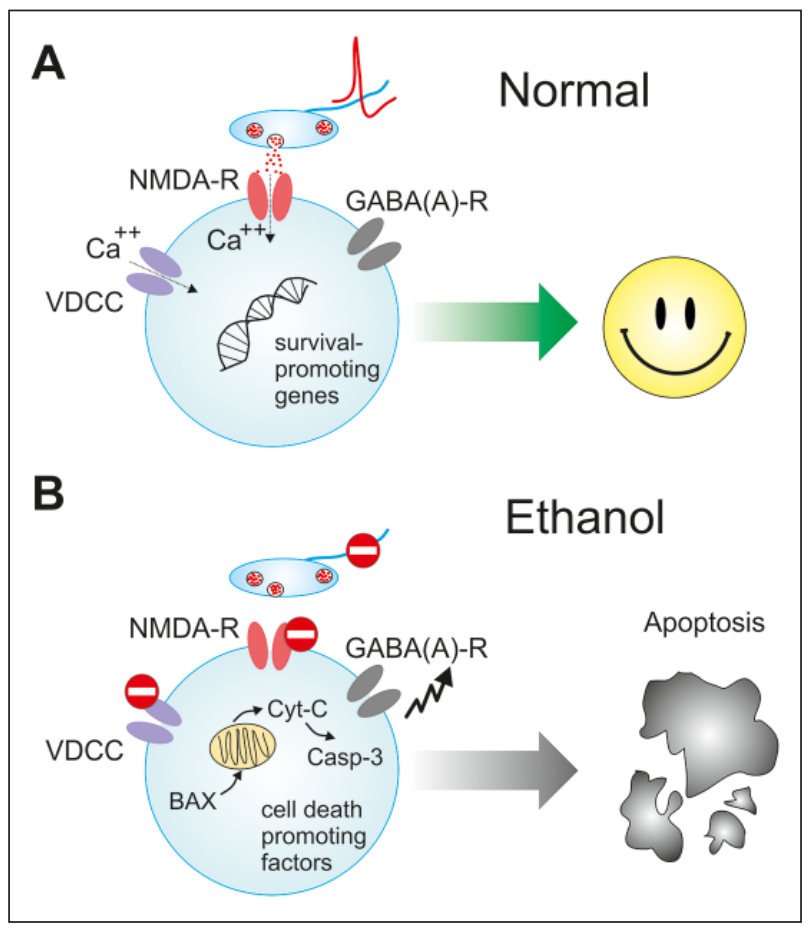

Figure I. Traditional views on the effects of ethanol on the developing brain. (A) During development, activity-dependent mechanisms control neuronal survival through a regulation of apoptosis. Neurons that participate in the network driven activity display intracellular calcium transients mediated by entry of calcium through $\mathrm{N}$-methyl-D-aspartate (NMDA) receptors at glutamatergic synapses and through voltagegated calcium channels (VDCCs) activated during neuronal firing. These calcium transients activate survival-promoting genes that enable neurons to build up a neuroprotective shield against apoptosis. (B) Ethanol acts on multiple targets in the immature neurons including direct inhibition of NMDA receptors and VDCCs and potentiation of GABAergic inhibition. This is supposed to inhibit neuronal activity that also results in a suppression of glutamate release. Altogether, this leads to a suppression of the intracellular calcium transients and to an activation of the intrinsic apoptotic pathway that involves translocation of proapoptotic members of the $\mathrm{Bcl}-2$ family, such as Bax protein, to the mitochondrial membrane and release of cytochrome $c$ and the initiation of a cascade of events leading to activation of caspase- 3 .

processes including cell neuronal differentiation, migration, axon pathfinding, synapse formation and synaptic plasticity (Blankenship and Feller 2010; Colonnese and Khazipov 2012; Luhmann and others 2016). During the period of the most intense synaptogenesis occurring in the first two postnatal weeks in rodents and during the second half of gestation in humans, the cerebral cortex displays synchronized network activity characterized by intermittent bursts organized in oscillations in alpha-beta (spindle bursts) and gamma (early gamma oscillations, EGOs) frequency ranges (for reviews, see Colonnese and Khazipov 2012; HanganuOpatz 2010; Khazipov and Luhmann 2006; Khazipov and 
others 2013; Luhmann and others 2016). These early activity patterns are internally generated in the thalamocortical circuits as evidenced by thalamocortical recordings and their persistence after sensory deafferentation, but they can also be triggered by peripheral sensory inputs in intact behaving animals (Akhmetshina and others 2016; Minlebaev and others 2011; Yang and others 2013; Yang and others 2009). In the somatosensory cortex, they are driven by sensory feedback resulting from myoclonic twitches (Akhmetshina and others 2016; Khazipov and others 2004; Tiriac and others 2012). In the visual cortex, before the onset of vision, they are driven by spontaneous retinal waves (Colonnese and Khazipov 2010; Hanganu and others 2006). Similar patterns of electrical activity are observed in the human brain in the second half of gestation (Colonnese and Khazipov 2012; Khazipov and Luhmann 2006). These early oscillatory patterns are generated by activation of ionotropic glutamate AMPA/kainate and NMDA receptors, and GABAergic interneurons support these oscillations in a developmental manner, compartmentalizing the activated cortical areas via surround inhibition (Kirmse and others 2015; Minlebaev and others 2007; Minlebaev and others 2009; Minlebaev and others 2011). Blockade of ionotropic glutamate receptors using antagonists applied to the cortical surface completely suppresses the early activity bursts. Whole-cell recordings and pharmacological analysis have revealed that AMPA/kainate receptors are instrumental for the generation of the fast oscillatory component of the early activity bursts, whereas NMDA receptors contribute to the generation of the slow delta component through an efficient temporal summation of slow NMDA receptor mediated synaptic currents during rhythmic activity of the thalamic inputs (Minlebaev and others 2007; Minlebaev and others 2009; Minlebaev and others 2011). Immature excitatory cortical neurons are also connected via gap-junctions that participate in the synchronization of the neocortical spontaneous plateau assemblies and carbachol-induced beta oscillations during the first days after birth in vitro (Allene and others 2008; Dupont and others 2006). However, blockade of cortical gap-junctions increased frequency of spindle-bursts and boosted their delta-component suggesting that electrical synapses play inhibitory roles in the generation of spindle-bursts in vivo (Minlebaev and others 2007; Minlebaev and others 2009). Recruitment of the GABAergic circuit to the early activity bursts rapidly develops during the first two postnatal weeks with the formation of transient circuits (Daw and others 2007; Minlebaev and others 2011). The effects of the agents acting on GABA(A) receptors differ depending on the postnatal age. Perisomatic feedforward inhibition and inhibitionbased gamma rhythmogenesis emerges at the end of the first postnatal week both in the neocortex and hippocampus and GABA receptor blockers have little effect on cortical gamma rhythmogenesis during the early postnatal days as during this period, cortical early gamma oscillations (EGOs) are primarily generated by feedforward gamma rhythmic thalamic excitation (Daw and others 2007; Minlebaev and others 2011). Starting from the end of the first postnatal week, GABA receptor blockers suppress both feedforward inhibition and EGOs (Daw and others 2007; Minlebaev and others 2011). Also, blockade of GABA(A) receptors evokes epileptiform events in the infragranular layers as early as at P2, and these epileptiform events spread horizontally with an important contribution of NMDA synapses in the corticocortical connections and activate the thalamus through the corticothalamic projections in thalamocortical slices (Golshani and Jones 1999; Kilb and others 2013; Wells and others 2000). Cortical application of GABA(A) blockers on the neonatal cortex in vivo also increases the size of the cortical areas activated during spindle-bursts, whereas enhancement of the GABAergic transmission using positive allosteric modulators of GABA(A) receptors such as benzodiazepines reduces the frequency of cortical bursts and the size of the activated cortical areas (Kirmse and others 2015; Minlebaev and others 2007; Minlebaev and others 2009). Also, optogenenetic stimulation of interneurons reduces the frequency of glutamatergic currents both in the neocortex and hippocampus of neonatal mice (Valeeva and others 2016). Taken together, these results indicate that activity in the neonatal neocortex is primarily driven by glutamatergic connections with GABAergic interneurons playing mainly inhibitory roles in the developing cortical networks.

In the developing hippocampus, the first organized activity pattern is intermittent sharp waves (SPWs) and activity bursts often occurring following SPWs (SPW-tail sequence). These also involve co-activation of glutamatergic and GABAergic synapses in their generation (Leinekugel and others 2002). This pattern shares some similar features with the giant depolarizing potentials (GDPs) in hippocampal slices and intact hippocampus in vitro (Ben-Ari and others 1989). Generation of GDPs involves local glutamatergic circuitry and depolarizing GABAergic connections. Whole-cell analysis of the conductances activated during GDPs and complete blockade of GDPs by ionotropic glutamate receptor antagonists indicates pivotal roles of glutamatergic circuits in GDP generation (Bolea and others 1999; Khalilov and others 2015). GABAergic involvements in GDPs are more complex. On one hand, GABA depolarizes and excites immature hippocampal neurons in vitro and suppression of the depolarizing action of GABA using the NKCC1 antagonist bumetanide suppresses GDPs, indicating that depolarizing GABA is instrumental in GDP generation (Dzhala and others 2005). On the other hand, GABA also exerts inhibitory actions. Partial blockade of GABA(A) receptors increases neuronal firing and synchronization during GDPs, whereas their complete inhibition evokes epileptiform discharges (Khalilov and others 1999; Lamsa and others 2000; Valeeva and others 2010). The positive allosteric 
modulator of GABA(A) receptors diazepam increases GDP frequency but reduces neuronal firing and synchronization during GDPs and slows down GDP propagation (Galindo and others 2005; Valeeva and others 2010). These data are consistent with a model of dual (both excitatory and inhibitory) GABA actions. How GABAergic circuits shape hippocampal network activity during SPWs and "tails" in vivo is poorly understood at present, but in keeping with the recent findings, the balance in the excitatory and inhibitory GABAergic actions at the network level maybe shifted toward inhibition in the neonatal hippocampus in vivo (Valeeva and others 2016).

All the above information on the circuits involved in the generation of the early activity patterns in the developing cortex, and their pharmacological properties are important for an understanding of the neuroapoptotic actions of various agents, including ethanol, because these early activity patterns appear to be essential in controlling developmental neuroapoptosis. Considerable evidence indicates that physiological activity in developing networks prevents developmental apoptosis and that synaptic activity-dependent neuronal survival is induced by calcium entry through synaptic NMDA receptors and voltage-gated calcium channels, and activation of survival-promoting genes that enable neurons to build up a neuroprotective shield (Golbs and others 2011; Hagenston and Bading 2011; Heck and others 2008; Ikonomidou and others 1999; Kilb and others 2011; Leveille and others 2010; Mennerick and Zorumski 2000; Nimmervoll and others 2013). Indeed, blockade of NMDA receptors causes widespread apoptotic neurodegeneration in the neonatal rat brain in vivo and this brain injury can be partially reversed by the calcium channel agonist BayK 8644 (Ikonomidou and others 1999; Turner and others 2009). NMDA antagonists also trigger apoptotic death of cultured hippocampal neurons, which is associated with decreased neuronal activation and intracellular calcium (Hwang and others 1999; Xu and others 2000). In organotypic neocortical slice cultures of newborn mice, blockade of spontaneous network bursts by tetrodotoxin and ionotropic glutamate receptor antagonists causes a significant increase in the number of apoptotic neurons as early as 6 hours after the start of drug treatment (Heck and others 2008). Boosting network activity by increasing the concentration of extracellular potassium, or by the application of 4-aminopyridine or the GABA(A) receptor antagonist gabazine causes a reduction or delay in caspase-3 activation and an overall increase in neuronal survival (Golbs and others 2011). The drugs that potentiate GABAmediated inhibition also induce cell death and these effects are counteracted by agents that increase excitation or induce increased intracellular calcium levels (Ikonomidou and others 2000; Xu and others 2000). Taken together, these observations suggest that physiological activity in developing networks prevents developmental apoptosis and that suppression of early activity could be a common denominator in the neuroapoptogenic actions of agents that suppress neuronal activity (Creeley and Olney 2013).

\section{Ethanol-Induced Neuroapoptosis in the Developing Brain}

Massive neuroapoptosis induced by ethanol exposure in the developing brain was first documented in rats in a seminal study by J. W. Olney and colleagues (Ikonomidou and others 2000). The authors described several important features of this phenomenon, including age dependency of the ethanol-induced apoptosis in different forebrain regions, and showed that the effects of ethanol are mimicked by blockers of NMDA receptors and positive allosteric modulators of GABA(A) receptors, the two putative targets of ethanol at the molecular level (Lovinger and others 1989; Masood and others 1994; Mody and others 2007; Wright and others 1996). Notably, different brain regions displayed different developmental windows of susceptibility to the apoptotic action of ethanol. The peak of the ethanol induced apoptosis in the ventromedial, mediodorsal, and ventral thalamus was observed around birth; in the subiculum, caudate thalamus, and laterodorsal and anteroventral thalamus at around P3 and in the cerebral cortex at around P7. Therefore, the ethanol-induced apoptosis seems to involve different neuronal populations depending on their age. While all types of neurons are susceptible to the apoptotic actions of ethanol, there are some particularly vulnerable cortical populations including L5 pyramidal cells and neurons located at the boarder of L2/1 (Lebedeva and others 2017; Olney and others 2002b) (Fig. 2C-E), interneurons (Ogievetsky and others 2016), neurons in hilar region (West and others 1986) (Fig. 3B), Purkinje cells and other neurons in the cerebellar cortex, deep cerebellar nuclei, brainstem nuclei (Bauer-Moffett and Altman 1977; Dikranian and others 2005), neurons in the caudate nucleus, nucleus accumbens, hypothalamus, amygdala (Ikonomidou and others 2000); retina and superior colliculus (Tenkova and others 2003). Ethanol also triggers apoptosis in glia, including oligodendrocytes (Creeley and Olney 2013).

Ethanol-induced apoptotic neurodegeneration is an intrinsic pathway apoptotic phenomenon that involves translocation of proapoptotic members of the Bcl-2 family, such as Bax protein, to the mitochondrial membrane and release of cytochrome $\mathrm{c}$ due to increased permeability of the latter and the initiation of a cascade of events leading to activation of caspase-3 (Young and others 2003; Young and others 2005). Suppression of phosphorylation of extracellular signal-regulated kinases (ERK), which is a signaling system that regulates cell survival, appears to play a key role in the apoptogenic effects of ethanol, as lithium, which counteracts the suppressant action of ethanol on pERK efficiently protects against 


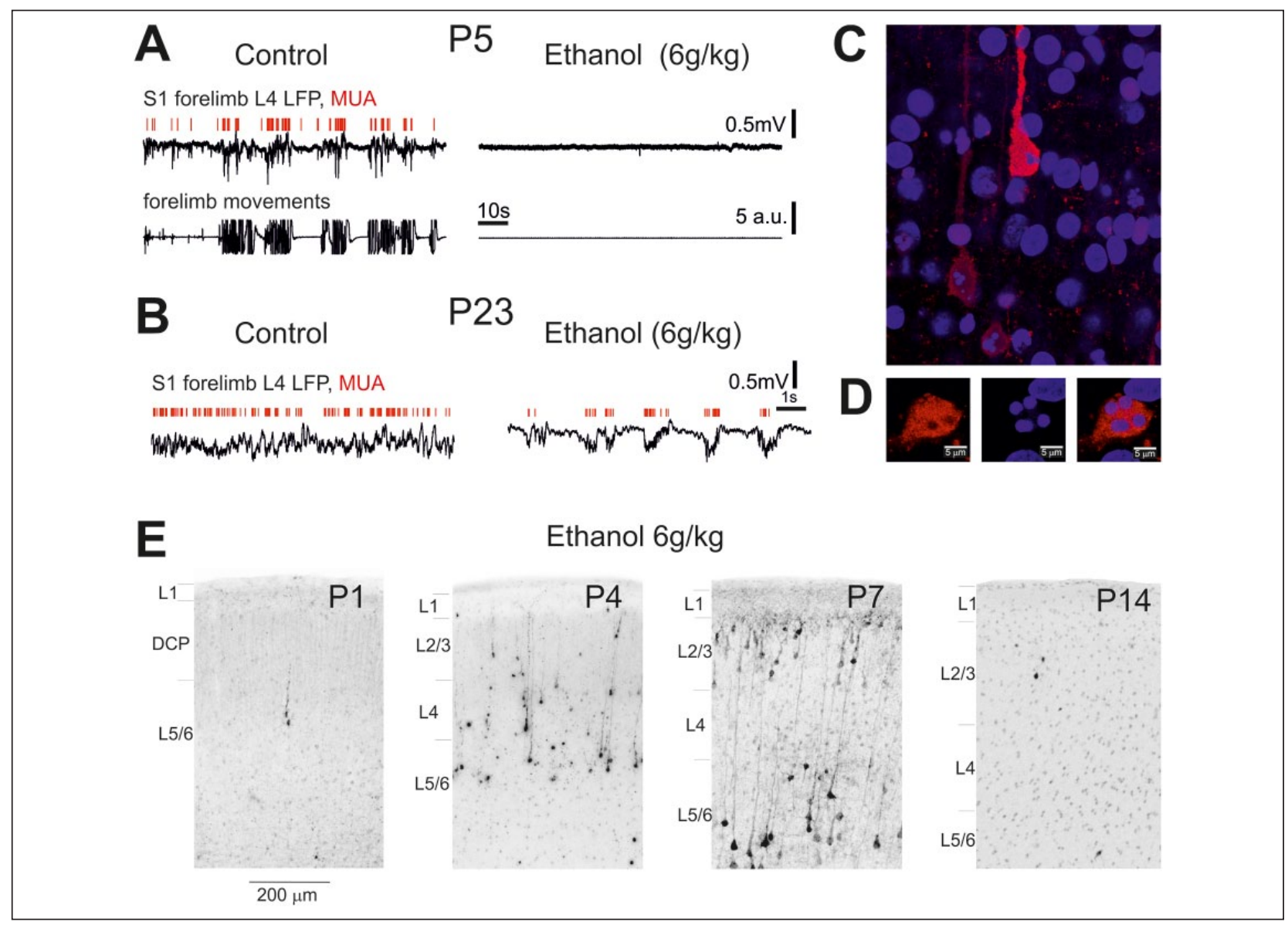

Figure 2. Age dependence of the effects of ethanol on the activity and apoptosis in the rat somatosensory cortex. (A, B) Effects of ethanol on spontaneous activity in the primary somatosensory cortex of P5 (A) and P23 (B) rats. Example traces of spontaneous electrical activity in L4 of the forelimb representation in the SI cortex (local field potential [LFP]—black traces; multiple unit activity [MUA] — red bars above) in control conditions (left) and 10 minutes after intraperitoneal injection of $20 \%$ ethanol at $6 \mathrm{~g} / \mathrm{kg}$ (right). (C) Morphological features of ethanol-induced apoptosis in the neonatal rat barrel cortex. Confocal image of L5 of the barrel cortex of a P7 rat treated with $6 \mathrm{~g} / \mathrm{kg}$ ethanol ( $20 \% \mathrm{wv}$, intraperitoneally). The sections were stained with antibodies against activated caspase-3 (red) and DAPI (4',6-diamidino-2-phenylindole) staining of the chromatin (blue). Note DAPI-stained apoptotic bodies in the active caspase-3 stained neurons. (D) Example of the body of an apoptotic neuron with a caspase-3 signal showing chromatin condensation into apoptotic bodies. (E) Histological sections from the SI cortex of rats at different postnatal ages 8 hours after treatment with ethanol $(6 \mathrm{~g} / \mathrm{kg}, 20 \% \mathrm{wv}$, intraperitoneally). Sections have been stained with antibodies to activated caspase-3. Adapted with modifications from (Lebedeva and others 2017).

apoptogenic injury induced by ethanol in the immature brain (Young and others 2008; Zhong and others 2006) (for reviews, see Creeley and Olney 2013; Farber and Olney 2003; Ikonomidou 2009; Luo 2012; Mennerick and Zorumski 2000; Nikolic and others 2013; Olney 2014; Olney and others 2004).

\section{Inhibitory Effects of Ethanol on Neuronal Activity in the Developing Cortex}

The effects of ethanol on the neuronal activity in the developing cortex were first explored using patch clamp recordings and fluorometric imaging of intracellular calcium ions in hippocampal slices of neonatal P3-7 rats (Galindo and others 2005). Under control conditions, the activity was characterized by recurrent GDPs in the hippocampal neurons (Ben-Ari and others 1989). Bathapplication of ethanol produced an up to several-fold concentration-dependent increase in GDP frequency and calcium transients and these effects were fully reversible after washout of the drug. The main effects at the synaptic level involved an increase in the frequency of the pharmacologically isolated spontaneous GABA(A) and AMPA receptor-mediated postsynaptic currents (PSCs) in the pyramidal cells and GABA(A)-PSCs in interneurons, and an increase in the frequency of miniature GABA(A)-mPSCs at CA3 interneurons. Ethanol did not 


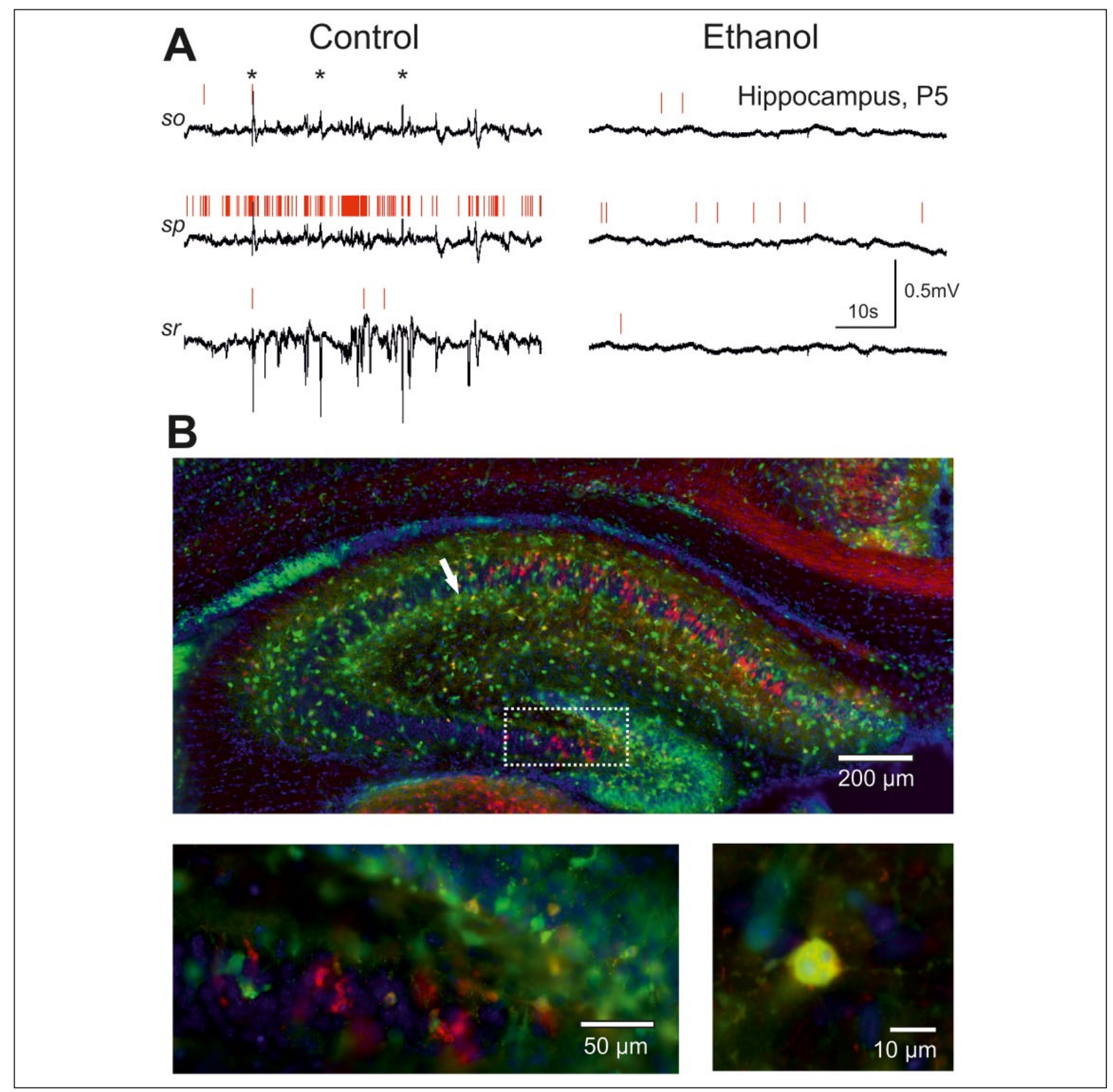

Figure 3. Effects of ethanol on the hippocampal activity in newborn rat. (A) Example traces of CAI hippocampal activity at different depths in a P6 rat before (left) and 30 minutes after the administration of ethanol (right). (B) Ethanol-induced apoptosis of interneurons revealed with cleaved capase-3 immunochemistry in the hippocampus of GAD67-GFP mouse line. Confocal image of the hippocampus of a GAD67-GFP mouse at P5 treated with $6 \mathrm{~g} / \mathrm{kg}$ ethanol ( $20 \% \mathrm{wv}$, intraperitoneally). The sections were stained with antibodies against activated caspase-3 (red) and DAPI (4',6-diamidino-2-phenylindole) staining of the chromatin (blue). GFP fluorescence (green) and GFP + activated caspase-3 co-staining (yellow). The boxed area and example of the apoptotic interneuron indicated by an arrow are shown at higher magnification in the bottom panel. Adapted with modifications from Chernova and others (20I7) and Ogievetsky and others (20I6).

affect the intrinsic excitability of CA3 pyramidal cells and interneurons, or the glutamatergic interictal-like discharges induced by blockade of GABA(A) receptors. On the basis of these data, it was suggested that ethanol stimulates neonatal neuronal networks and that this effect is driven mainly by an increase in the synaptic release and excitatory actions of GABA. These findings challenged the view that ethanol depresses neuronal activity during early stages of development, an assumption made from the depressant actions of ethanol in adult brain, where ethanol shifts the balance between excitatory and inhibitory neurotransmission toward inhibition (Harris 1999). 


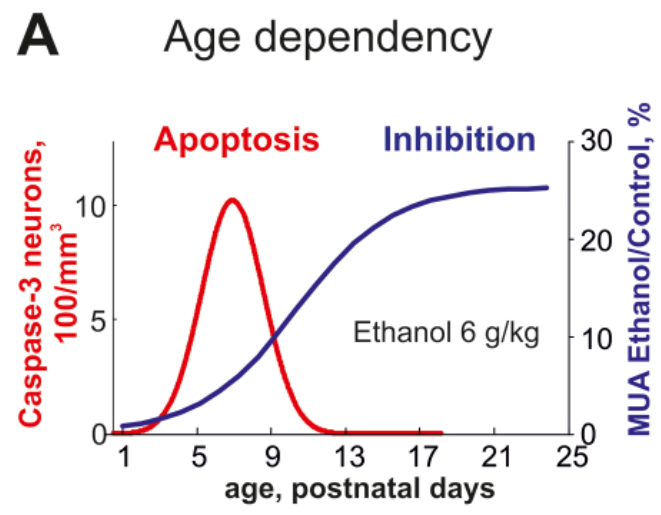

\section{B Dose dependency}

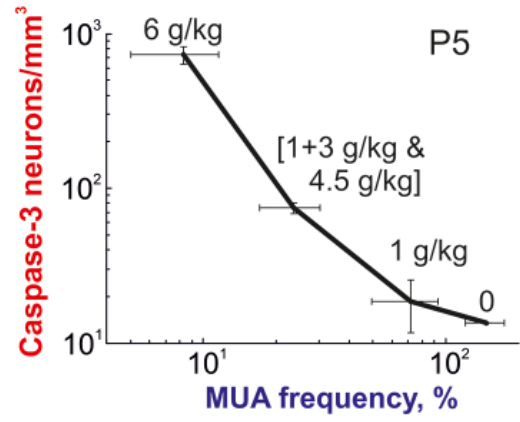

Figure 4. Summary of the age and dose dependency of the ethanol-induced neuroapoptosis and inhibition of SI cortical activity in developing rats. (A) Developmental profiles of the ethanol-induced neuroapoptosis and inhibitory effects of ethanol on neuronal firing expressed as a Boltzman fit of the age-dependence of multiple unit activity (MUA) inhibition in the developing rat SI cortex. Note that ethanol almost completely suppresses neuronal activity during the first postnatal week, when the neuroapoptotic actions of ethanol attain maximal values. However, the neurotoxic actions of ethanol only occur within a critical developmental window and inhibition per se is not sufficient to trigger massive apoptosis at PI-2, where the inhibition of cortical activity is most robust. (B) The correlation between the ethanol-induced apoptosis and suppression of SI activity (MUA frequency after ethanol administration normalized to control values) at different doses of ethanol. Note high correlation levels between the dose-dependent ethanol-induced cortical inhibition and apoptosis. Adapted with modifications from Lebedeva and others (2017).

These observations also evidently go against the hypothesis that the apoptogenic actions of alcohol in the immature brain involve suppression of brain activity. However, how alcohol acts on the immature brain activity in vivo still has not been shown.

This question has been addressed recently in the somatosensory cortex and hippocampus of neonatal rats. In a study by Lebedeva and colleagues (Lebedeva and others 2017), recordings of spontaneous and sensory-evoked electrical activity were performed in the primary somatosensory cortex of head-restrained, non-anaesthetized rats and the ageand dose-dependence of the effects of ethanol on cortical activity was compared to the ethanol-induced apoptosis using cleaved caspase-3 staining, a sensitive measure of ethanol-induced apoptotic neurodegeneration (Ikonomidou and others 2000; Olney and others 2002a) (Fig. 2). It was found that at P4-7, when the peak of ethanol-induced apoptosis was observed in the somatosensory cortex, ethanol strongly suppressed spontaneous gamma oscillations and spindle-bursts and almost completely silenced neurons in a dose-dependent manner. In agreement with previous studies (Ikonomidou and others 2000), the neurotoxic threshold of the action of ethanol was in the range of $>200 \mathrm{mg} / \mathrm{dL}$, and below this threshold, ethanol exerted only mild suppressive effects on S1 activity. At ethanol levels above this threshold, the dose-dependence of suppression of neuronal activity strongly correlated with the ethanol-induced neuroapoptosis (Fig. 4B). The suppressive effects of ethanol on neuronal activity waned during the second and third postnatal weeks, when instead of silencing the cortex, ethanol evoked delta wave electrographic activity (Figs. 2A and 4A). Thus, the effects of ethanol on brain activity are strongly age-dependent, and during the first postnatal week alcohol profoundly inhibits brain activity. However, there was no full match in the developmental profiles of the ethanol-induced neuroapoptosis, which was characterized by a bell-shaped curve, and the inhibitory effects of ethanol on cortical activity, which were characterized by sigmoidal age-dependence (Fig. 4A). Particularly prominent dissociation between these parameters was observed in P1-2 animals, where the neuroapoptotic effects of ethanol were minimal but the suppression of S1 activity by ethanol was particularly robust, indicating that inhibition of activity per se is not sufficient to trigger massive apoptosis at P1-2. This is in keeping with the hypothesis that suppression of activity could only trigger apoptosis within a critical developmental window of vulnerability, occurring in various brain regions and neuronal populations at different ages (Ikonomidou and others 2000).

At least two mechanisms may contribute to the effects of ethanol on the early cortical activity. First, profound ethanol-induced suppression of the cortical activity was also associated with inhibition of spontaneous motor activity. Because the main physiological drive for the early oscillatory bursts in the somatosensory cortex involves sensory feedback resulting from spontaneous motor activity, including myoclonic twitching (Akhmetshina and others 2016; Inacio and others 2016; Khazipov and others 2004; Mohns and Blumberg 2010; Tiriac and others 2012), inhibition of spontaneous 
motor activity by ethanol in neonatal rat pups eliminates the physiological trigger for the cortical activity bursts thus contributing to the depressant effects of ethanol on cortical activity. Second, ethanol also inhibited responses evoked by sensory stimulation indicating that ethanol inhibits the thalamocortical circuits generating early activity bursts. As described above, generation of the thalamocortical early gamma oscillations and spindle-bursts during the first postnatal week primarily involves activation of the AMPA/kainate and NMDA receptors at glutamatergic synapses whereas cortical GABAergic interneurons play mainly inhibitory roles. Ethanol is a non-competitive inhibitor of NMDA receptors affecting ion channel gating (Lovinger and others 1989; Wright and others 1996). Importantly, ethanol preferentially inhibits NMDA receptors containing the NR2B subunit (Masood and others 1994), which is preferentially expressed and is responsible for the long decay of NMDA receptor mediated synaptic currents in cortical neurons during the first postnatal week (Monyer and others 1994). Ethanol may also inhibit extrasynaptic NMDA receptors activated by glutamate spillover (Allene and others 2008). In addition, ethanol also inhibits the kainate type of glutamate receptors, prominently expressed in the cortex during the early postnatal period (Dildymayfield and Harris 1995; Kidd and Isaac 1999). On the other hand, ethanol potentiates GABA(A) receptors with a particularly strong action on $\delta$ subunit containing $\operatorname{GABA}(\mathrm{A})$ receptors, which mediate tonic current (Kilb and others 2013; Mody and others 2007), and may increase quantal GABA release from interneurons (Galindo and others 2005). Ethanol may also inhibit gap-junctions (Stobbs and others 2004) but this mechanism is unlikely involved as the blockers of gap-junctions potentiate spindle-burst activity (Minlebaev and others 2007; Minlebaev and others 2009). Thus, the inhibitory effects of ethanol on cortical activity in neonatal rats likely involve (1) peripheral inhibitory actions of ethanol on spinal cord-generated movements, which normally trigger S1 bursts via sensory feedback and (2) central inhibitory actions of ethanol on NMDA and kainate receptors and enhancement of the GABA(A) receptor functions that inhibit early oscillatory thalamocortical activity patterns. This is also in accordance with nearly complete inhibition of S1 activity in rat pups by combined administration of the NMDA receptor antagonist ketamine and the positive GABA(A) receptor allosteric modulator midazolam (Lebedeva and others 2016). Thus, mimicking the effects of ethanol on its presumed main targets - that is, suppression of NMDA receptors and potentiation of GABAergic transmission - produces inhibition of the cortical activity, which is very similar to the ethanol-induced inhibition of activity, and stimulates neuroapoptosis in the neonatal rat pups (Ikonomidou and others 2000; Young and others 2005).

These findings are also in keeping with the apoptogenic (Jevtovic-Todorovic and others 2003) and powerful inhibitory effects of the general anesthetic isoflurane on cortical activity specifically during the first postnatal week, when this agent totally suppresses spontaneous activity bursts and neuronal firing and inhibits sensoryevoked bursts, similarly to ethanol (Sitdikova and others 2014). Interestingly, the inhibitory effects of isoflurane on cortical activity are observed during its exposure and they rapidly wane after isoflurane withdrawal (Sitdikova and others 2014) while the apoptogenic effects of the latter require long-lasting, not less than 4 to 6 hours, exposure to the drug (Jevtovic-Todorovic and others 2003). This is in compliance with the in vitro studies, where promotion of apoptosis was observed after 6 hours of the activity blockade (Heck and others 2008). A single administration of ethanol at doses evoking cortical neuroapoptosis produces rapid suppression of cortical activity lasting for more than 4 hours. Taken together, these findings suggest that the minimal period of the activity blockade required for stimulation of apoptosis is in the range of several hours, which is achieved in the case of isoflurane by continuous exposure to the drug and in the case of a single administration of alcohol by elevated ethanol levels lasting for several hours after injection (see also Ikonomidou and others 2000).

Profound ethanol-induced inhibition of activity was also observed in the neonatal (P4-6) rat hippocampus in vivo (Chernova and others 2017) (Fig. 3A). Early SPWs, which are the first and the most prominent pattern of the organized activity in the neonatal hippocampus, were strongly suppressed by ethanol in a dose-dependent manner. This was associated with a reduction in the neuronal firing, and at concentrations inducing massive neuroapoptosis in the hippocampus, both SPWs and hippocampal multiple unit activity was almost completely abolished, with the inhibitory effects lasting for several hours. These results differ from the stimulation of the activity described in hippocampal slices of neonatal rats in vitro, where ethanol was shown to stimulate neuronal activity and increase the frequency of GDPs (see above) (Galindo and others 2005). Although the reasons for this discrepancy in the ethanol actions on hippocampal activity in vivo and in vitro are unknown, it is plausible that it involves an inhibition of spontaneous movements that may trigger hippocampal SPWs (Karlsson and others 2006) and an increase in GABAergic transmission by ethanol (Galindo and others 2005) yet with a difference in the network function of the GABAergic interneurons in vitro and in vivo. As discussed above, GABA, acting via GABA(A) receptors exerts, during the neonatal period, complex excitatory and inhibitory network actions in the hippocampus in vitro, 


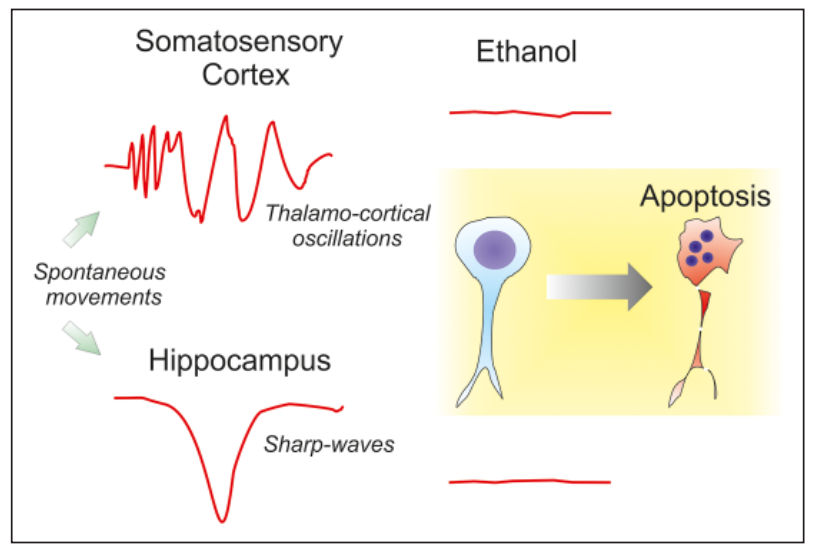

Figure 5. Schematic diagram summarizing the effects of ethanol on the developing brain. In control condition (left traces), early activity patterns of early gamma and spindleburst oscillations in somatosensory cortex and sharp-waves in hippocampus that are triggered by sensory feedback from spontaneous movements drive intracellular calcium oscillations and prevent from apoptosis. Ethanol completely suppresses neuronal activity through a suppression of spontaneous movements and an inhibition of the thalamocortical circuits. This removes a neuroprotective shield supported by the early activity patterns and leads to a massive neuroapoptosis mediated by the activation of caspase- 3 and associated with nuclear and cellular degradation.

and its depolarizing/excitatory facet is instrumental for GDP generation. Enhancement of GABAergic transmission by ethanol should stimulate neuronal networks and increases GDPs frequency in vitro, similar to the effects of GABA(A) receptor agonists (Dzhala and others 2005), positive allosteric modulators (Galindo and others 2005; Valeeva and others 2010), or optogenetic activation of interneurons (Valeeva and others 2016). Yet in the intact animal in vivo, the only available evidence so far suggests that GABAergic interneurons exert a mainly inhibitory function in the neonatal hippocampus (Valeeva and others 2016). In keeping with these findings, enhancement of GABAergic transmission by ethanol should result in inhibitory effects on the developing hippocampal network activity in vivo.

\section{Conclusions}

Thus, during the critical developmental period of vulnerability, ethanol strongly inhibits brain activity and the level of the ethanol-induced suppression of activity matches the dose-dependence of the ethanol-induced neuroapoptosis. The inhibitory effects of ethanol on cortical activity are age dependent: In neonatal animals, ethanol nearly completely suppresses multiple unit activity and flattens the electrocorticogram, profoundly inhibiting the early activity patterns of spindle-bursts and early gamma oscillations in the neocortex and the early SPWs in the hippocampus, while in adult animals, ethanol only mildly depresses neuronal firing and induces delta-wave activity. Suppression of cortical activity in neonatal animals likely involves an inhibition of myoclonic twitches, an important physiological trigger for the early activity bursts, and inhibition of the thalamocortical circuits through a potentiation of GABAergic transmission and an inhibition of NMDA receptors. Together, these findings provide full support for the hypothesis that the ethanol-induced inhibition of cortical activity is an important pathophysiological mechanism underlying massive neuroapoptosis induced by ethanol in the developing brain and the adverse lifelong neurological and behavioral consequences of fetal ethanol exposure (Fig. 5).

\section{Declaration of Conflicting Interests}

The author(s) declared no potential conflicts of interest with respect to the research, authorship, and/or publication of this article.

\section{Funding}

The author(s) disclosed receipt of the following financial support for the research, authorship, and/or publication of this article: This work was supported by INSERM (LIA), the subsidy allocated to Kazan University for the state assignment in the sphere of scientific activities (№ 6.2313.2017/4.6) and the program of competitive growth of Kazan University.

\section{References}

Akhmetshina D, Nasretdinov A, Zakharov A, Valeeva G, Khazipov R. 2016. The nature of the sensory input to the neonatal rat barrel cortex. J Neurosci 36(38):9922-32.

Allene C, Cattani A, Ackman JB, Bonifazi P, Aniksztejn L, Ben-Ari Y, and others. 2008. Sequential generation of two distinct synapse-driven network patterns in developing neocortex. J Neurosci 28(48):12851-63.

Bauer-Moffett C, Altman J. 1977. The effect of ethanol chronically administered to preweanling rats on cerebellar development: a morphological study. Brain Res 119(2):249-68.

Ben-Ari Y, Cherubini E, Corradetti R, Gaiarsa J-L. 1989. Giant synaptic potentials in immature rat CA3 hippocampal neurones. J Physiol 416:303-25.

Bittigau P, Sifringer M, Genz K, Reith E, Pospischil D, Govindarajalu S, and others. 2002. Antiepileptic drugs and apoptotic neurodegeneration in the developing brain. Proc Natl Acad Sci U S A 99(23):15089-94.

Blankenship AG, Feller MB. 2010. Mechanisms underlying spontaneous patterned activity in developing neural circuits. Nat Rev Neurosci 11(1):18-29.

Bolea S, Avignone E, Berretta N, Sanchez-Andres JV, Cherubini E. 1999. Glutamate controls the induction of GABA-mediated giant depolarizing potentials through AMPA receptors in neonatal rat hippocampal slices. J Neurophysiol 81(5):2095-102. 
Chernova K, Burkhanova G, Zakharov A, Khazipov R, Sitdikova G. 2017. Inhibitory effects of ethanol in the neonatal rat hippocampus in vivo. BioNanoScience 7:159.

Colonnese MT, Khazipov R. 2010. "Slow activity transients" in infant rat visual cortex: a spreading synchronous oscillation patterned by retinal waves. J Neurosci 30(12):4325-37.

Colonnese M, Khazipov R. 2012. Spontaneous activity in developing sensory circuits: Implications for resting state fMRI. Neuroimage 62(4):2212-21.

Creeley CE, Olney JW. 2013. Drug-induced apoptosis: mechanism by which alcohol and many other drugs can disrupt brain development. Brain Sci 3(3):1153-81.

Daw MI, Ashby MC, Isaac JT. 2007. Coordinated developmental recruitment of latent fast spiking interneurons in layer IV barrel cortex. Nat Neurosci 10(4):453-61.

Dikranian K, Qin YQ, Labruyere J, Nemmers B, Olney JW. 2005. Ethanol-induced neuroapoptosis in the developing rodent cerebellum and related brain stem structures. Dev Brain Res 155(1):1-13.

Dildymayfield JE, Harris RA. 1995. Ethanol inhibits kainate responses of glutamate receptors expressed in xenopus oocytes - role of calcium and protein-kinase-C. J Neurosci 15(4):3162-71.

Dunty WC Jr, Chen SY, Zucker RM, Dehart DB, Sulik KK. 2001. Selective vulnerability of embryonic cell populations to ethanol-induced apoptosis: implications for alcoholrelated birth defects and neurodevelopmental disorder. Alcohol Clin Exp Res 25(10):1523-35.

Dupont E, Hanganu IL, Kilb W, Hirsch S, Luhmann HJ. 2006. Rapid developmental switch in the mechanisms driving early cortical columnar networks. Nature 439(7072):79-83.

Dzhala VI, Talos DM, Sdrulla DA, Brumback AC, Mathews GC, Benke TA, and others. 2005. NKCC1 transporter facilitates seizures in the developing brain. Nat Med 11(11):1205-13.

Farber NB, Olney JW. 2003. Drugs of abuse that cause developing neurons to commit suicide. Dev Brain Res 147(12):37-45

Galindo R, Zamudio PA, Valenzuela CF. 2005. Alcohol is a potent stimulant of immature neuronal networks: implications for fetal alcohol spectrum disorder. J Neurochem 94(6):1500-11.

Girault V, Gilard V, Marguet F, Lesueur C, Hauchecorne M, Ramdani Y, and others. 2017. Prenatal alcohol exposure impairs autophagy in neonatal brain cortical microvessels. Cell Death Dis 8(2):e2610.

Golbs A, Nimmervoll B, Sun JJ, Sava IE, Luhmann HJ. 2011. Control of programmed cell death by distinct electrical activity patterns. Cereb Cortex 21(5):1192-202.

Golshani P, Jones EG. 1999. Synchronized paroxysmal activity in the developing thalamocortical network mediated by corticothalamic projections and "silent" synapses. J Neurosci 19(8):2865-75.

Hagenston AM, Bading H. 2011. Calcium signaling in synapseto-nucleus communication. Cold Spring Harb Perspect Biol 3(11):a004564.

Hanganu IL, Ben Ari Y, Khazipov R. 2006. Retinal waves trigger spindle bursts in the neonatal rat visual cortex. J Neurosci 26(25):6728-36.
Hanganu-Opatz IL 2010. Between molecules and experience: role of early patterns of coordinated activity for the development of cortical maps and sensory abilities. Brain Res Rev 64(1):160-76.

Harris RA. 1999. Ethanol actions on multiple ion channels: which are important? Alcohol Clin Exp Res 23(10): 1563-70

Heck N, Golbs A, Riedemann T, Sun JJ, Lessmann V, Luhmann HJ. 2008. Activity-dependent regulation of neuronal apoptosis in neonatal mouse cerebral cortex. Cereb Cortex. 18(6):1335-49.

Hwang JY, Kim YH, Ahn YH, Wie MB, Koh JY. 1999. $N$-methyl-D-aspartate receptor blockade induces neuronal apoptosis in cortical culture. Exp Neurol 159(1):124-30.

Ikonomidou C. 2009. Triggers of apoptosis in the immature brain. Brain Dev. 31(7):488-92.

Ikonomidou C, Bittigau P, Ishimaru MJ, Wozniak DF, Koch C, Genz K, and others. 2000. Ethanol-induced apoptotic neurodegeneration and fetal alcohol syndrome. Science 287(5455):1056-60.

Ikonomidou C, Bosch F, Miksa M, Bittigau P, Vöckler J, Dikranian K, and others. 1999. Blockade of NMDA receptors and apoptotic neurodegeneration in the developing brain. Science 283(5398):70-4.

Inacio AR, Nasretdinov A, Lebedeva J, Khazipov R. 2016. Sensory feedback synchronizes motor and sensory neuronal networks in the neonatal rat spinal cord. Nat Commun 7:13060.

Jevtovic-Todorovic V, Hartman RE, Izumi Y, Benshoff ND, Dikranian K, Zorumski CF, and others. 2003. Early exposure to common anesthetic agents causes widespread neurodegeneration in the developing rat brain and persistent learning deficits. J Neurosci 23(3):876-82.

Jégou S, El Ghazi F, de Lendeu PK, Marret S, Laudenbach V, Uguen A, and others. 2012. Prenatal alcohol exposure affects vasculature development in the neonatal brain. Ann Neurol 72(6):952-60.

Karlsson KA, Mohns EJ, di Prisco GV, Blumberg MS. 2006. On the co-occurrence of startles and hippocampal sharp waves in newborn rats. Hippocampus. 16(11):959-65.

Khalilov I, Dzhala V, Ben-Ari Y, Khazipov R. 1999. Dual role of GABA in the neonatal rat hippocampus. Dev Neurosci. 21(3-5):310-9.

Khalilov I, Minlebaev M, Mukhtarov M, Khazipov R. 2015. Dynamic changes from depolarizing to hyperpolarizing GABAergic actions during giant depolarizing potentials in the neonatal rat hippocampus. J Neurosci 35(37):12635-42.

Khazipov R, Luhmann HJ. 2006. Early patterns of electrical activity in the developing cerebral cortex of humans and rodents. Trends Neurosci 29(7):414-8.

Khazipov R, Minlebaev M, Valeeva G. 2013. Early gamma oscillations. Neuroscience 250:240-52.

Khazipov R, Sirota A, Leinekugel X, Holmes GL, Ben Ari Y, Buzsaki G. 2004. Early motor activity drives spindle bursts in the developing somatosensory cortex. Nature 432(7018):758-61.

Kidd FL, Isaac JT. 1999. Developmental and activity-dependent regulation of kainate receptors at thalamocortical synapses. Nature 400(6744):569-73. 
Kilb W, Kirischuk S, Luhmann HJ. 2011. Electrical activity patterns and the functional maturation of the neocortex. Eur J Neurosci 34(10):1677-86.

Kilb W, Kirischuk S, Luhmann HJ. 2013. Role of tonic GABAergic currents during pre- and early postnatal rodent development. Front Neural Circuits 7:139.

Kirmse K, Kummer M, Kovalchuk Y, Witte OW, Garaschuk O, Holthoff K. 2015. GABA depolarizes immature neurons and inhibits network activity in the neonatal neocortex in vivo. Nat Commun 6:7750.

Lamsa K, Palva JM, Ruusuvuori E, Kaila K, Taira T. 2000. Synaptic GABA(A) activation inhibits AMPA-kainate receptor-mediated bursting in the newborn (P0-P2) rat hippocampus. J Neurophysiol 83(1):359-66.

Lebedeva J, Zakharov A, Ogievetsky E, Minlebaeva A, Kurbanov R, Gerasimova E, and others. 2017. Inhibition of cortical activity and apoptosis caused by ethanol in neonatal rats in vivo. Cereb Cortex 27(2):1068-82.

Lebedeva YA, Zakharova AV, Sitdikova GF, Zefirov AL, Khazipov RN. 2016. Ketamine-midazolam anesthesia induces total inhibition of cortical activity in the brain of newborn rats. Bull Exp Biol Med 161(1):15-19.

Leinekugel X, Khazipov R, Cannon R, Hirase H, Ben Ari Y, Buzsaki G. 2002. Correlated bursts of activity in the neonatal hippocampus in vivo. Science 296(5575):2049-52.

Leveille F, Papadia S, Fricker M, Bell KF, Soriano FX, Martel MA, and others. 2010. Suppression of the intrinsic apoptosis pathway by synaptic activity. J Neurosci 30(7):2623-35.

Lovinger DM, White G, Weight FF. 1989. Ethanol inhibits NMDA-activated ion current in hippocampal neurons. Science 243(4899):1721-4.

Luhmann HJ, Sinning A, Yang JW, Reyes-Puerta V, Stuttgen MC, Kirischuk S, and others. 2016. Spontaneous neuronal activity in developing neocortical networks: from single cells to large-scale interactions. Front Neural Circuits. 10:40.

Luo J. 2012. Mechanisms of ethanol-induced death of cerebellar granule cells. Cerebellum. 11(1):145-54.

Masood K, Wu CP, Brauneis U, Weight FF. 1994. Differential ethanol sensitivity of recombinant $N$-methyl-D-aspartate receptor subunits. Mol Pharmacol 45(2):324-9.

Mattson SN, Crocker N, Nguyen TT. 2011. Fetal alcohol spectrum disorders: neuropsychological and behavioral features. Neuropsychol Rev 21(2):81-101.

Mennerick S, Zorumski CF. 2000. Neural activity and survival in the developing nervous system. Mol Neurobiol. 22(13):41-54.

Minlebaev M, Ben-Ari Y, Khazipov R. 2009. NMDA receptors pattern early activity in the developing barrel cortex in vivo. Cereb Cortex. 19(3):688-96.

Minlebaev M, Ben-Ari Y, Khazipov R. 2007. Network mechanisms of spindle-burst oscillations in the neonatal rat barrel cortex in vivo. J Neurophysiol 97(1):692-700.

Minlebaev M, Colonnese M, Tsintsadze T, Sirota A, Khazipov R. 2011. Early gamma oscillations synchronize developing thalamus and cortex. Science 334(6053):226-9.

Mody I, Glykys J, Wei WZ. 2007. A new meaning for "gin \& tonic": tonic inhibition as the target for ethanol action in the brain. Alcohol 41(3):145-53.
Mohns EJ, Blumberg MS. 2010. Neocortical activation of the hippocampus during sleep in infant rats. J Neurosci 30(9):3438-49.

Monyer H, Burnashev N, Laurie DJ, Sakmann B, Seeburg PH. 1994. Developmental and regional expression in the rat brain and functional properties of four NMDA receptors. Neuron 12(3):529-40.

Morton RA, Valenzuela CF. 2016. Further characterization of the effect of ethanol on voltage-gated $\mathrm{Ca}^{2+}$ channel function in developing CA3 hippocampal pyramidal neurons. Brain Res 1633:19-26.

Nikolic M, Gardner HA, Tucker KL. 2013. Postnatal neuronal apoptosis in the cerebral cortex: physiological and pathophysiological mechanisms. Neuroscience 254:369-78.

Nimmervoll B, White R, Yang JW, An SM, Henn C, Sun JJ, and others. 2013. LPS-induced microglial secretion of TNF alpha increases activity-dependent neuronal apoptosis in the neonatal cerebral cortex. Cereb Cortex 23(7):1742-55.

Ogievetsky E, Lotfullina N, Minlebaeva A, Khazipov R. 2016. Ethanol-induced apoptosis of interneurons in the neonatal GAD67-GFP mouse hippocampus. BioNanoScience. Epub Oct. doi:10.1007/s12668-016-0334-6.

Olney JW, Tenkova T, Dikranian K, Muglia LJ, Jermakowicz WJ, D'Sa C , and others. 2002a. Ethanol-induced caspase-3 activation in the in vivo developing mouse brain. Neurobiol Dis 9(2):205-19.

Olney JW, Tenkova T, Dikranian K, Qin YQ, Labruyere J, Ikonomidou C. 2002b. Ethanol-induced apoptotic neurodegeneration in the developing C57BL/6 mouse brain. Dev Brain Res 133(2):115-26.

Olney JW, Young C, Wozniak DF, Jevtovic-Todorovic V, Ikonomidou C. 2004. Do pediatric drugs cause developing neurons to commit suicide? Trends Pharmacol Sci 25(3):135-9.

Olney JW. 2014. Focus on apoptosis to decipher how alcohol and many other drugs disrupt brain development. Front Pediatr 2:81.

Sitdikova G, Zakharov A, Janackova S, Gerasimova E, Lebedeva J, Inacio AR, and others. 2014. Isoflurane suppresses early cortical activity. Ann Clin Transl Neurol. 1(1):15-26.

Stobbs SH, Ohran AJ, Lassen MB, Allison DW, Brown JE, Steffensen SC. 2004. Ethanol suppression of ventral tegmental area GABA neuron electrical transmission involves $N$-methyl-D-aspartate receptors. J Pharmacol Exp Ther 311(1):282-9.

Tenkova T, Young C, Dikranian K, Labruyere J, Olney JW. 2003. Ethanol-induced apoptosis in the developing visual system during synaptogenesis. Invest Ophthalmol Vis Sci 44(7):2809-17.

Tiriac A, Uitermarkt BD, Fanning AS, Sokoloff G, Blumberg MS. 2012. Rapid whisker movements in sleeping newborn rats. Curr Biol 22(21):2075-80.

Turner CP, DeBenedetto D, Liu C. 2009. NMDAR blockadeinduced neonatal brain injury: reversal by the calcium channel agonist BayK 8644. Neurosci Lett 450(3):292-5.

Valeeva G, Abdullin A, Tyzio R, Skorinkin A, Nikolski E, BenAri $Y$, and others. 2010. Temporal coding at the immature depolarizing GABAergic synapse. Front Cell Neurosci 4. 
Valeeva G, Tressard T, Mukhtarov M, Baude A, Khazipov R. 2016. An optogenetic approach for investigation of excitatory and inhibitory network GABA actions in mice expressing channelrhodopsin-2 in GABAergic neurons. J Neurosci 36(22):5961-73.

Wells JE, Porter JT, Agmon A. 2000. GABAergic inhibition suppresses paroxysmal network activity in the neonatal rodent hippocampus and neocortex. J Neurosci 20(23):8822-30.

West JR, Hamre KM, Cassell MD. 1986. Effects of ethanol exposure during the third trimester equivalent on neuron number in rat hippocampus and dentate gyrus. Alcohol Clin Exp Res 10(2):190-7.

Wright JM, Peoples RW, Weight FF. 1996. Single-channel and whole-cell analysis of ethanol inhibition of NMDAactivated currents in cultured mouse cortical and hippocampal neurons. Brain Res. 738(2):249-56.

$\mathrm{Xu} \mathrm{W}$, Cormier R, Fu T, Covey DF, Isenberg KE, Zorumski $\mathrm{CF}$, and others. 2000. Slow death of postnatal hippocampal neurons by $\mathrm{GABA}_{\mathrm{A}}$ receptor overactivation. J Neurosci 20(9):3147-56.

Yang JW, An S, Sun JJ, Reyes-Puerta V, Kindler J, Berger T, and others. 2013. Thalamic network oscillations synchronize ontogenetic columns in the newborn rat barrel cortex. Cereb Cortex 23(6):1299-316.

Yang JW, Hanganu-Opatz IL, Sun JJ, Luhmann HJ. 2009. Three patterns of oscillatory activity differentially synchronize developing neocortical networks in vivo. J Neurosci 29(28):9011-25.

Young C, Klocke BJ, Tenkova T, Choi J, Labruyere J, Qin YQ, and others. 2003. Ethanol-induced neuronal apoptosis in vivo requires $\mathrm{BAX}$ in the developing mouse brain. Cell Death Differ 10(10):1148-55.

Young C, Roth KA, Klocke BJ, West T, Holtzman DM, Labruyere J, and others. 2005. Role of caspase-3 in ethanol-induced developmental neurodegeneration. Neurobiol Dis 20(2):608-14.

Young CL, Straiko MM, Johnson SA, Creeley C, Olney JW. 2008. Ethanol causes and lithium prevents neuroapoptosis and suppression of pERK in the infant mouse brain. Neurobiol Dis 31(3):355-60.

Zhong J, Yang XL, Yao WG, Lee WH. 2006. Lithium protects ethanol-induced neuronal apoptosis. Biochem Biophys Res Commun 350(4):905-10. 